\title{
Anterior lenticonus and the Waardenburg syndrome
}

\author{
P. R. STEVENS
}

Blackburn, Lancs.

Anterior lenticonus is a rare condition in which there is a conical forward protrusion of the axial portion of the anterior capsule of the lens and anterior cortex which usually remains clear. The nucleus is not involved, indicating that the anomaly develops relatively late. Males are more commonly affected than females and in most cases both eyes are involved. Some of the cases reported in the literature are associated with Alport's syndrome, which comprises hereditary chronic progressive nephritis and perceptive deafness and is usually transmitted as an autosomal dominant trait (Arnott, Crawfurd, and Toghill, r966).

In the patient reported below bilateral anterior lenticonus is associated with the Waardenburg syndrome, a feature of which is hereditary perceptive deafness, and which also has an autosomal dominant mode of inheritance. According to Duke-Elder (1964) some cases may occur sporadically.

\section{Case report}

A man born in 1946 first attended the out-patients department in February, 1967 , complaining of progressive deterioration of the visual acuity in each eye and increasing deafness for several months. There was no past or recent history of head or ocular injury, or of ocular or otological disease. He had had uncomplicated mumps at the age of 15 years but there was no other significant medical history. No members of his family were known to suffer from deafness. His paternal grandmother had senile cataracts.

\section{Examination}

He had a well-marked white forelock. The fronto-nasal angle was absent, the root of the nose was broad and prominent, and the eyebrows were confluent across the prominence (synophrys). Although the root of the nose was broad the internal canthi were not displaced laterally and the lower lacrimal puncta were in normal apposition to the eyeballs. His hearing was impaired and he appeared to lip-read with difficulty.

Biomicroscopy of the right eye showed a small vesicle beneath the axial portion of the anterior capsule which was pushed forward as a conical projection into the anterior chamber. Behind the vesicle was a localized anterior polar cataract. The lens nucleus was not involved and was clear. The visual acuity was $6 / 60$.

The left eye showed a small rupture in the anterior capsule, in the lower outer quadrant of the lens approximately $3 \mathrm{~mm}$. away from the optic axis, through which opaque lens cortex was extruded into the anterior chamber. The visual acuity was reduced to hand movements at one metre.

Each cornea showed a well-defined arcus juvenilis. There was no evidence of uveitis in either eye. Apart from a small benign melanoma of the iris of the right eye there was no disturbance of iris pigmentation nor any evidence of hypoplasia of the iris stroma.

The Wassermann reaction, gonococcal complement-fixation test, and Price's precipitation reaction were negative. 


\section{Investigations}

Pure-tone audiography confirmed a severe bilateral perceptive deafness (Figure).
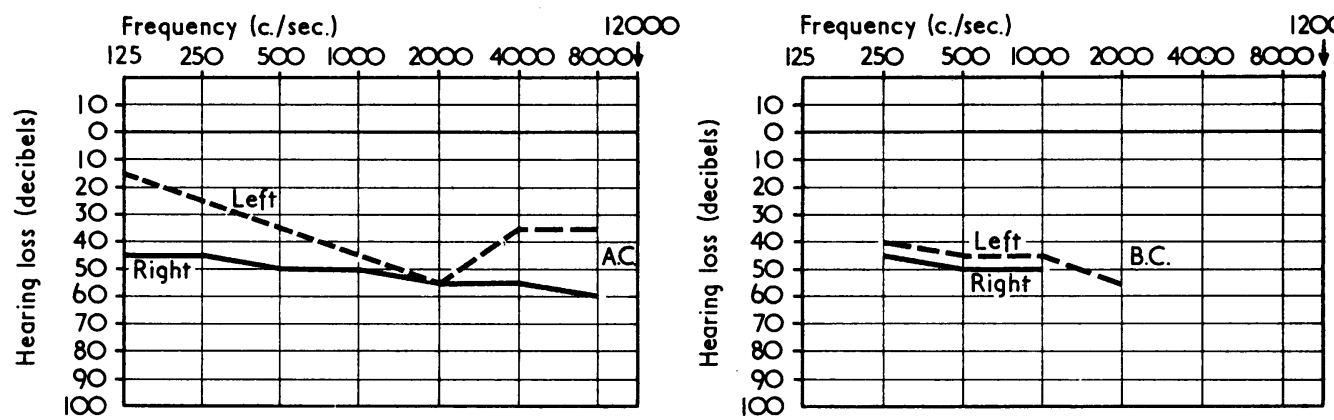

$\begin{array}{llllllll}25 & 250 & 500 & 1000 \quad 2000 & 40008000\end{array}$

FIGURE Audiogram 22.2.67, showing bilateral severe perceptive deafness. There was no bone conduction after $2,000 \mathrm{c} / \mathrm{sec}$.

Haemoglobin I 8 per cent. Erythrocyte sedimentation rate $3 \mathrm{~mm} . / \mathrm{sst} \mathrm{hr}$ (Westergren). Serum proteins 6.9 per cent.; albumin 3.5 per cent.; globulin 3.4 per cent.; A/G ratio $1.03:$ I. Serum cholesterol $198 \mathrm{mg} . / 100 \mathrm{ml}$. Toxoplasma dye test positive at a dilution of $\mathbf{~}: 8$.

$X$ rays of the chest and paranasal sinuses normal. Urine analysis normal.

\section{Progress}

The patient was admitted to hospital for observation and treatment. One week after admission the anterior lenticonus of the right lens ruptured spontaneously and the anterior polar cataract wos $\vec{\theta}$ immediately extruded into the anterior chamber. Thereafter the lens of each eye developed totait. cataract which absorbed slowly over a period of 5 months.

\section{Treatment}

He was re-admitted to hospital in July, 1967 , and a discission of the posterior capsule of the right eye was performed. The visual acuity of this eye improved to $6 / 9$, with +12 D sph., +0.5 D cyl., $\varrho$ axis $90^{\circ}$. Discission of the posterior capsule of the left eye followed and the visual acuity of this eye $\vec{\circ}$ also improved to $6 / 9$ with a spectacle lens of the same power. The gap obtained in the posterior 3 capsule of the left eye was small and some proliferation of the capsular epithelium necessitated a second discission. This was carried out during January, 1970, and was followed by restoration of $6 / 9$ vision.

\section{Discussion}

Arnott and others ( 1966 ) reviewed 42 cases of anterior lenticonus reported in the literature and added a new case of their own. Twelve of the reported cases ( 28 per cent.) were associated with Alport's syndrome. Anterior lenticonus, or indeed any other form of lens anomaly, has not been hitherto described in association with the Waardenburg syndrome which, when fully expressed, comprises the following features, listed in order of the degree $N$ of penetrance from high to low (Waardenburg, I95I):

(a) Lateral displacement of the inner canthi,

(b) Broadness and prominence of the root of the nose,

(c) Confluence of the eyebrows,

(d) Heterochromia iridum,

(e) Congenital perceptive deafness, and

(f) White forelock. 
The feature common to the two syndromes is perceptive deafness. Ocular defects are not uncommonly found in association with syndromes of deafness of either genetic or congenital origin. In the syndromes under discussion, disturbances of the ocular neuroectoderm, hypoplasia of the iris stroma, and hypopigmentation of the fundus (Hass and Tan, I966) are linked with perceptive deafness in the Waardenburg syndrome, and anomalies of the lens, anterior and posterior lenticonus, lentiglobus, and spherophakia are linked with Alport's syndrome. The case described differs from the usual pattern-a lens anomaly is involved in the Waardenburg syndrome in which the expected ocular defect is an abnormality of uveal pigmentation-and this is probably a chance occurrence. In this case there was no hereditary element and the syndrome was incompletely expressed, in that dystopia of the inner canthi and heterchromia iridum were not present. The other features of the syndrome were definite and the perceptive deafness was severe.

Probably the most interesting feature of this case is the spontaneous rupture of the lens capsule, a rare event which has so far been described in detail in only two patients with anterior lenticonus (Ehrlich, I946; Gregg and Backer, I963). The lens capsule in cases of anterior lenticonus has been found to be thinned and stretched, the number of epithelial cells being less than normal (Duke-Elder, I964), and this accounts for the ease with which spontaneous rupture occurs. The cause of the defect is still a matter for conjecture.

Comparing his case with those described by Jaworski (1910), Tsukahara (1930), and Feigenbaum (1932), in which anterior polar cataracts developed, Ehrlich (1946) suggested that a self-healing spontaneous rupture of the lenticonus probably accounted for the change from anterior lenticonus to anterior polar cataract. However, the present case and that described by Gregg and Becker (1963) demonstrate that an anterior polar cataract can antedate the rupture of the lenticonus.

The remaining feature of interest is the arcus juvenilis, the significance of which is not clear. There was no evidence of degenerative corneal disease or hypercholesterolaemia. The case of anterior lenticonus and Alport's syndrome described by Arnott and others ( I966) also had this feature and they observed that it was also present in a similar case described by Tsukahara (1930).

\section{Summary}

A case of bilateral anterior lenticonus with spontaneous rupture of the anterior lens capsule is described and compared with two other reported cases of this rare anomaly. The lens defects were associated with the Waardenburg syndrome.

\section{References}

ARNOtT, e. J., CRAWFURD, M. D'A., and toghill, P. J. (1966) Brit. F. Ophthal., 50, 390 DUKE-ELDER, s. (1964) “System of Ophthalmology", vol. 3, pt. 2, p. I I43. Kimpton, London (1969) Ibid., vol. I1, p. 6o

EHRLich, L. H. (1946) Amer. F. Ophthal., 29, 1274

FEIGENBAUM, A. (1932) Folia ophthal. orient., 1, 103

GREGG, J. B., and BECKer, S. F. (1963) Arch. Ophthal. (Chicago), 69, 293

hAAS, E. B. H. DE, and TAN, K. E. W. P. (I966) Docum. ophthal. (Den Haag), 2r, 239

JAWORSKI, A. (1910) Arch. Augenheilk., 65, 313

TSUKAhara, y. (1930) Acta Soc. ophthal. Jap., 34, 370

WAARDENBURG, P. J. (195I) Amer. F. hum. Genet., 3, 195 